\title{
From the Cradle to the Grave: Age Differences in Attachment From Early Adulthood to Old Age
}

Journal of Personality 81:2, April 2013

(C) 2012 Wiley Periodicals, Inc.

DOI: 10.1 III/j.1467-6494.20I2.00793.x

\author{
William J. Chopik,' Robin S. Edelstein,' and \\ R. Chris Fraley ${ }^{2}$ \\ 'University of Michigan, Ann Arbor \\ ${ }^{2}$ University of Illinois, Urbana-Champaign
}

\begin{abstract}
Objective: Although attachment dynamics are thought to be important across the life span, relatively few studies have examined attachment processes beyond young adulthood. Extant research on age differences in attachment orientation has yielded conflicting results and interpretations. The purpose of this study was to provide a more complete picture of age-related differences in attachment anxiety and avoidance.

Method: We examined attachment anxiety and avoidance in 86,555 Internet respondents $(71.8 \%$ female) ranging in age from 18 to 70.

Results: We found that attachment anxiety was highest among younger adults and lowest among middle-aged and older adults. Attachment avoidance showed less dramatic age differences overall but was highest among middle-aged adults and lowest among younger and older adults. In addition, partnered individuals reported lower levels of attachment anxiety and avoidance compared to single individuals, particularly in younger and older adulthood. Women also reported slightly higher anxiety and avoidance compared to men, especially in young adulthood.
\end{abstract}

Conclusions: Findings are discussed in the context of life span changes in social roles, normative personality development, and emotion regulation throughout adulthood.

Keywords: attachment, personality development, age differences, anxiety, avoidance

More than 40 years have passed since John Bowlby (1969/ 1982) proposed that the attachment system is influential "from the cradle to the grave" (p. 208). During those years, researchers have documented many important links between individual differences in attachment and behavior, emotion, and cognition in close relationships (Cassidy \& Shaver, 2008). Yet the majority of this work has focused on early childhood and young adulthood. Relatively little attention has been paid to attachment processes from a life span perspective - one that includes middle and older adulthood (Magai, 2008). A life span perspective can provide a valuable framework for attachment research. Indeed, many attachment-relevant phenomena are likely to occur after young adulthood (e.g., marriage, bereavement, caregiving for an elderly parent; see Magai, 2008). Before we can fully understand how attachment dynamics unfold in middle and older adulthood, it is important to understand how attachment orientations differ by age and the factors that may be associated with these differences.

The objective of this article is to take an important step toward a more complete understanding of attachment by addressing two unresolved questions about life span attachment processes: (a) Do attachment orientations differ by age? and (b) Are these age differences moderated by gender and relationship status? Prior work has yielded inconsistent findings about the nature and direction of age differences in attachment, in part because most studies have relied on relatively small sample sizes and/or narrow age ranges. Yet there are reasons to expect attachment orientations, like other personality constructs (Srivastava, John, Gosling, \& Potter, 2003), to show meaningful age-related differences. In addition, although research has shown that young adults' attachment orientations differ according to their gender and relationship status (Del Giudice, 2011; Noftle \& Shaver, 2006), few studies have examined whether these differences are observed across the life span.

The first author was supported by a National Science Foundation Graduate Research Fellowship.

We thank Ethan Kross and members of the Personality, Cognition, and Emotion lab for their comments on earlier versions of this article.

Correspondence concerning this article should be addressed to William J. Chopik, Department of Psychology, University of Michigan, 530 Church Street, Ann Arbor, MI 48109. Email: chopik@umich.edu. 
To redress these important gaps in the literature, we investigated age differences in attachment avoidance and anxiety in a large, cross-sectional sample of adults ranging in age from 18 to 70 . We also examined the extent to which gender and relationship status were associated with adult attachment orientations across the life span. It is our hope that this study will help to advance knowledge about the ways in which attachment varies across the life course.

\section{Age-Related Differences in Attachment Orientations}

An individual's attachment orientation is generally conceptualized as his or her position on two conceptually distinct dimensions: anxiety and avoidance (Fraley \& Waller, 1998). The anxiety dimension reflects concern over the availability and responsiveness of attachment figures (Mikulincer, Gillath, \& Shaver, 2002). For instance, individuals with higher attachment anxiety scores tend to worry about abandonment and become easily overwhelmed by interpersonal stressors (Mikulincer \& Florian, 1998). The avoidance dimension is characterized by chronic attempts to deactivate or inhibit attachment-system activation (Edelstein \& Shaver, 2004). For instance, individuals with higher avoidance scores tend to minimize expressions of distress (Fraley \& Shaver, 1997) and generally dislike physical and emotional intimacy (Brennan, Clark, \& Shaver, 1998). Individuals reporting low scores on both dimensions are generally considered secure. The anxiety and avoidance dimensions are thought to reflect variation in the functioning of the attachment behavioral system - a motivational system that originally evolved in the ecology of childhood but is also assumed to function in close relationships throughout the human life span (Fraley \& Shaver, 2000; Hazan \& Shaver, 1987).

Because the vast majority of attachment research has been conducted with young adults, relatively little is known about attachment processes in later life, including about life span differences in attachment orientations (Magai, 2008). Are there reasons to expect age-related differences? Roberts, Wood, and Smith (2005) have suggested that investing in and making commitments to social institutions are driving forces that can explain age differences in personality. Normative social roles (e.g., partnership, parenting) are often age-graded and come with sets of expectations that reward social maturity (Roberts et al., 2005). Because transitions in partnership and parenting generally occur throughout early and middle adulthood, one might therefore expect the largest differences in attachment to be observed during this time period.

Specific predictions about patterns of age differences can also be made based on normative changes in social roles. For instance, close relationships in early adulthood likely facilitate and demand increases in emotion-regulatory skills, which may lead to decreases in negative emotional experiences (e.g., Gross et al., 1997). Indeed, there is consistent evidence for age-related decreases in Neuroticism (Srivastava et al., 2003), a personality construct that shares some conceptual and empirical overlap with attachment anxiety (Noftle \& Shaver, 2006). There is also some evidence that these changes are largest during early to middle adulthood (Terracciano, McCrae, Brant, \& Costa, 2005). In a large cross-sectional sample of over 1 million participants, Soto, John, Gosling, and Potter (2011) observed higher levels of Neuroticism among young women compared to middle-aged and older women. Age differences in Neuroticism were much less pronounced among men, but older men had the lowest levels of Neuroticism in the sample.

Thus, we expected that attachment anxiety would be higher among younger adults and lower among middle-aged and older adults (i.e., in the period after which enduring intimate relationships are typically established). Extant research provides some support for this hypothesis. Specifically, in a longitudinal sample, Klohnen and John (1998) observed decreases in attachment anxiety among women from ages 27 to 52 . In cross-sectional studies, middle-aged (i.e., ages 40-60) and older (i.e., ages 60-88) individuals similarly report lower levels of attachment anxiety compared to their younger counterparts (i.e., ages 20-40; Diehl, Elnick, Bourbeau, \& Labouvie-Vief, 1998).

Transitions in life roles may also have implications for how attachment avoidance differs by age. High levels of avoidance in early adulthood could prevent the formation of intimate relationships altogether (Schindler, Fagundes, \& Murdock, 2010). However, literature on emerging adulthood (Arnett, 2000) suggests that changes during young adulthood could be accompanied by higher levels of attachment avoidance. Adolescents and young adults begin to explore their identities and develop more independence and autonomy as they approach their mid-20s (Erikson, 1968; Whitbourne \& Tesch, 1985). These individuation processes are also reflected in the shifting of attachment needs from parents to peers and romantic partners during adolescence and young adulthood (Fraley \& Davis, 1997). Age differences in avoidance would therefore be consistent with theory and research pointing to people's ability to revise existing attachment orientations in light of new information and experiences (Bowlby, 1973).

Age differences in avoidance may also be consistent with developmental differences in other personality traits that have some seemingly maladaptive qualities but may nevertheless be useful for establishing one's identity during young adulthood. For instance, for identity- and individuation-related purposes, researchers suggest that higher levels of traits like narcissism are beneficial specifically among young adults but not among middle-aged and older adults (Hill \& Roberts, 2012). Moreover, despite negligible correlations between avoidance and narcissism (e.g., Otway \& Vignoles, 2006), Smolewska and Dion (2005) suggest that these two personality constructs are conceptually similar, share an underlying structure, and serve similar purposes, in that both are the products of defense mechanisms employed to maintain a consistent self-concept. 
Thus, avoidance might be higher during time periods when this personality construct is considered more adaptive (i.e., during young adulthood).

Some support for the hypothesis that avoidance would be higher in middle adulthood comes from Mickelson, Kessler, and Shaver (1997), who found that avoidance was higher among middle-aged compared to young adults. Several other studies with large age ranges similarly find that avoidance is positively correlated with age (e.g., Birnbaum, 2007). Other studies show either no relationship or even a negative association with age (e.g., Noftle \& Shaver, 2006). However, many of these age differences are relatively small and/or utilize narrow age ranges, suggesting that large samples with wider age ranges may be necessary to detect them. Findings from another cross-sectional study suggest that attachment avoidance does not significantly differ among younger (ages 18-34) and older (ages 60-96) adults (Segal, Needham, \& Coolidge, 2009). Longitudinal research also provides little evidence for changes in avoidance in women from young to middle adulthood (Klohnen \& John, 1998).

Thus, extant research provides some evidence for agerelated differences in attachment orientation, particularly in early adulthood, such that anxiety is generally higher in younger compared to older adults and, in some studies, avoidance is higher in middle-aged compared to younger adults. However, several methodological considerations make it difficult to draw firm conclusions from this body of work. First, the majority of studies have utilized categorical measures of attachment (e.g., Diehl et al., 1998), which result in lower individual variability, less statistical power, and lower scale reliability than continuous measures (Fraley \& Waller, 1998). Second, prior samples include relatively narrow age ranges, making it difficult to obtain a comprehensive understanding of mean differences in attachment orientations throughout the adult life span. Such issues are particularly important if there are nonlinear associations between age and attachment, as is the case for many personality constructs (e.g., Srivastava et al., 2003). The current study addresses these concerns by utilizing a large cross-sectional sample with a wide age range (18-70 years old) and by using continuous measures of attachment.

\section{Moderators of Age-Related Differences in Attachment Orientations}

We also investigated factors that may be associated with adult attachment orientations across the life span. Prior research consistently indicates that individuals in romantic relationships are less anxious and avoidant (i.e., more secure) compared to single individuals (e.g., Edelstein \& Gillath, 2008). This may reflect the (potentially) security-enhancing effects of being in a relationship (Kirkpatrick \& Hazan, 1994). Secure individuals have many of the characteristics desirable in a long-term partner (e.g., attentiveness, warmth, sensitivity) and as such may be more likely to be in a relationship at any given time (Zeifman \& Hazan, 1997). Nevertheless, the extent to which being in a relationship is associated with attachment security across the life span is not yet clear. With age, individuals shift greater attention and resources toward maintaining intimate relationships (Carstensen, Isaacowitz, \& Charles, 1999), making such relationships increasingly central to personality development and functioning. Thus, the association between age and attachment security might be stronger among older compared to younger adults.

However, in a longitudinal study of newlyweds, attachment security increased even over the first few years of the relationship, despite overall decreases in marital satisfaction common among newlyweds (Davila, Karney, \& Bradbury, 1999). After examining a variety of individual-difference and contextual factors, Davila and colleagues suggested that increases in security can be attributed to people becoming more comfortable in their relationships, gaining more evidence that the relationship will last, and/or having spouses who serve attachment functions that promote close and intimate relations. Any of these scenarios support the claim that relationships serve a security-enhancing function. Lower levels of avoidance prior to relationship initiation also predict whether an individual will initiate a committed relationship, even after controlling for relationship goals and prior dating experience (Schindler et al., 2010). These findings suggest that individuals in relationships should have lower levels of anxiety and avoidance, but the association between age and security at different points in the life span is still an open question. Although cross-sectional data make it difficult to draw causal inferences about the association between security and relationship status, examining the moderating role of relationship status across the life span can provide an indirect test of these hypotheses.

A comprehensive study of attachment orientations across the life span can also provide valuable information about gender differences in attachment and the extent to which such differences vary by age. Some researchers suggest that, because women tend to be more relationship oriented than men (Cross \& Madson, 1997), women should report higher levels of attachment anxiety than men (Magai, Hunziker, Mesias, \& Culver, 2000). Men have been described as restricted in emotional expression and lower in emotionality (Consedine, Magai, \& Krivoshekova, 2005), leading to the prediction that men would report higher levels of attachment avoidance compared to women (Pietromonaco \& Carnelley, 1994). In a recent meta-analysis, Del Giudice (2011) found support for these predictions: Women generally scored higher on anxiety and men generally scored higher on avoidance, particularly in community samples. Moreover, gender differences in anxiety were largest in early adulthood, whereas differences in avoidance were smallest in early adulthood. These findings indicate that gender differences in attachment may not be static across the life course, possibly reflecting different socialization or maturation processes for men versus women. Understanding the magnitude of gender differences in attachment at different points in the life span can also provide information about how 
these processes may affect men and women differently. It is important to note, however, that Del Giudice's meta-analysis of gender differences was based on sample-level means, and he did not report the number of participants at various ages. Because the majority of samples in this meta-analysis appear to have an average age in the 20s (see Del Giudice, 2011, Table A1), the findings may not adequately reflect life span differences in attachment orientations. The current study allowed us to reexamine age-related differences in attachment by gender with a sample larger than Del Giudice's and with a larger number of participants at older ages. The findings from Del Giudice's meta-analysis suggest that men should report higher levels of attachment avoidance and women should report higher levels of attachment anxiety, but the magnitude of gender differences at different points in the life span is still an open question.

In sum, the present study redresses an important gap in the literature by examining age-related differences in attachment avoidance and anxiety in a large sample ranging in age from 18 to 70 . We examined whether avoidance and anxiety were associated with relationship status and gender, and whether these variables moderated any age differences in attachment orientations.

\section{METHOD}

\section{Participants and Procedure}

Data from 86,555 people $(71.8 \%$ female) were collected through the Web site yourpersonality.net, which contains a variety of Web studies and demonstrations about personality, attachment, and close relationships. Participants ranging in age from 18 to $70(M=30.70, S D=11.67)$ are included in the current report. An additional 12,869 individuals were excluded from the current analyses because they did not report their age, were younger than 18 or older than 70 (due to small sample sizes), did not complete the attachment measure, or submitted multiple responses (in such cases, only the initial set of responses was included). Most participants were from the United States (65.9\%), the United Kingdom (8.5\%), or Canada $(5.9 \%)$. Sixty-nine percent of participants reported that they were in an exclusive dating or marital relationship. ${ }^{1}$ Previous studies have shown that Internet-based samples can provide useful and valid data for psychological research (Srivastava et al., 2003). Moreover, such samples are often more diverse than traditional undergraduate samples with respect to age, ethnicity, nationality, relationship status, and income (Gosling, Vazire, Srivastava, \& John, 2004).

\section{Adult Attachment}

The 86,555 participants completed a subset of 20 (out of 36) items from the Experiences in Close Relationships-Revised (ECR-R) inventory (Fraley, Waller, \& Brennan, 2000), a widely used measure of individual differences in attachment avoidance and anxiety. The subset of items that each participant completed was randomly determined (as part of a larger psychometric study of existing attachment items), and on average participants answered the same number of items for both dimensions $(M=9.94)$. The ECR-R Attachment Avoidance subscale $(\alpha=.89)$ reflects an individual's discomfort with closeness. The Attachment Anxiety subscale $(\alpha=.88)$ reflects an individual's concern about abandonment. Sample items include "I don't feel comfortable opening up to romantic partners" (avoidance) and "I often worry that my partner doesn't really love me" (anxiety). Participants are asked to rate the extent to which they agree with each item on a scale ranging from 1 (strongly disagree) to 7 (strongly agree), and items are averaged to create subscales for avoidance $(M=2.98, S D=1.26)$ and anxiety $(M=3.52, S D=1.41)$.

\section{Considerations of Sample Size}

Large sample sizes, such as our own, have the benefit of being able to detect effects that are relatively small in magnitude; however, they can also lead to the detection of effects that are statistically "significant" but not practically meaningful. We adopted several established practices to increase our reliance on both meaningful and statistically significant effects. First, prior research suggests that the most complex age-personality relations that can be meaningfully interpreted involve cubic patterns (i.e., third-order terms; e.g., Terracciano et al., 2005), so we did not test more complex models. Second, following the recommendation of previous researchers in this area, we used a conservative approach of retaining only the terms that improved the overall model fit beyond a particular cut-off $(F>25$; Srivastava et al., 2003). In the current sample, this cut-off roughly corresponded to $\Delta R=.001$. All of our regression analyses also include an individual $F_{\text {change }}$ statistic for each term (see Table 2).

\section{RESULTS}

\section{Preliminary Analyses}

Zero-order correlations were calculated between the primary study variables (i.e., age, anxiety, avoidance, gender, and relationship status). Anxiety and avoidance were positively correlated, $r=.36, S E_{r}=.003$, and, consistent with prior research, participants in relationships reported lower levels of avoidance, $r=-.24, S E_{r}=.003$, and anxiety, $r=-.18, S E_{r}=.003$, compared to single participants, all $p \mathrm{~s}<.001$. Older participants were also more likely to be in a relationship, $r=.16$, $S E_{r}=.003, p<.001$. The remaining correlations were statistically significant but were less than $|.06|$ and thus unlikely to be of practical significance.

\section{Age Differences in Avoidance and Anxiety}

To examine broad age differences in the attachment dimensions, we divided individuals into six age groups. We created a 
Table I Means, Standard Deviations, and Reliabilities for the Attachment Dimensions by Age Group

\begin{tabular}{|c|c|c|c|c|c|c|}
\hline & \multicolumn{6}{|c|}{ Age Group } \\
\hline Sample size & 29,624 & 19,359 & 17,525 & 12,105 & 6,376 & 1,566 \\
\hline$\%$ Partnered & $56.6_{a}$ & $70.9_{b}$ & $77.4_{c}$ & $79.2_{d}$ & $76.6_{c}$ & $72.6_{b}$ \\
\hline$\%$ Female & $72.2_{a}$ & $72.2_{\mathrm{a}}$ & $72.7_{a}$ & $73 . I_{a}$ & $69.2_{\mathrm{b}}$ & $59.9_{c}$ \\
\hline \multicolumn{7}{|l|}{ Anxiety } \\
\hline \multicolumn{7}{|l|}{ Avoidance } \\
\hline$M(S D)$ & $2.88_{a}(1.23)$ & $2.94_{b}(1.25)$ & $3.08_{c}(1.27)$ & $3.12_{c}(1.29)$ & $3.04_{d}(1.30)$ & $3.06_{d}(I .3 I)$ \\
\hline Reliability $(\alpha)$ & .89 & .89 & .88 & .88 & .89 & .89 \\
\hline
\end{tabular}

young adulthood age group (18-22) to reflect the large number of participants (possibly college students) in this age range and also an early adulthood age group (23-29). The remaining ages were divided according to decades in the life span, a common approach in cross-sectional research (Terracciano et al., 2005). Analyses of the means by age group indicated that levels of anxiety were highest among younger and older adults. Avoidance was highest among middle-aged adults compared to younger and older adults. Results from these analyses, along with descriptive statistics for each age group, are presented in Table 1.

Next, to formally model associations between age and the attachment dimensions, we conducted hierarchical multiple regression analyses predicting avoidance and anxiety from the linear, quadratic $\left(\mathrm{age}^{2}\right)$, and cubic $\left(\mathrm{age}^{3}\right)$ effects of age. Age was centered prior to analysis, and the centered age term was used to compute the higher-order terms.

Using these criteria, we found that the quadratic effect of age was the best fit to the data for attachment anxiety, $\beta=-.07$, $R=.06, F(2,86,552)=154.37, p<.001$ : Anxiety was lower in early adults, higher in young adults, and lower in middle-aged and older adults. The linear term was also significant for anxiety, $\beta=.02, p<.001$, indicating a small (overall) increase with age (perhaps reflecting the increase in early adulthood). The quadratic effect was also the best fit for avoidance, $\beta=-.05, R=.07, F(2,86,552)=205.97, p<.001$. Avoidance was lower in younger adults, higher among middle-aged adults, and slightly lower in older adults. ${ }^{2}$ The linear term was also significant for avoidance, $\beta=.09, p<.001$, reflecting an overall increase with age. These findings are depicted in Figure 1.

\section{Effects of Relationship Status and Gender on Attachment Orientations}

Next, we examined whether age differences in attachment were moderated by gender and relationship status. Gender and relationship status were included in the hierarchical regression analyses described above, along with their interactions with each other and age, age $^{2}$, and age $^{3}$. Gender and relationship status were contrast-coded prior to computing the interaction terms. The inclusion of the quadratic terms significantly increased the amount of variance explained for anxiety, $F_{\text {change }}=130.96, p<.001$, and avoidance, $F_{\text {change }}=122.64$, $p<.001 .^{3}$

Results from these analyses are presented in Table 2. Using the criterion described above, we focus our discussion on coefficients whose individual inclusion in the model leads to an $F_{\text {change }}>25$. For anxiety, the main effects of age, age ${ }^{2}$, gender, and relationship status were statistically significant. The effects of age and age $^{2}$ replicate those described above. The $\mathrm{Age}^{2} \times$ Gender interaction also came very close to reaching our $F_{\text {change }}$ threshold. As depicted in Figure 2a, anxiety was higher among single compared to partnered participants at each point in the adult life span. As shown in Figure 3a, anxiety was also higher among women compared to men, particularly in young adulthood.

For avoidance, significant main effects of age, age $^{2}$, gender, and relationship status emerged. The effects of age and age $\mathrm{e}^{2}$ replicate those described above. These effects were qualified by significant two-way interactions between age and relationship status, gender and relationship status, and age ${ }^{2}$ and relationship status. As depicted in Figure 2b, avoidance was higher among single compared to partnered participants, and this difference was largest in young adulthood. The Gender $\times$ Relationship Status interaction (not pictured) revealed that single women reported especially high levels of avoidance. ${ }^{4}$

Because avoidance and anxiety were correlated, we created residualized anxiety and avoidance scores by predicting anxiety scores from avoidance scores and saving the residuals (and vice versa for avoidance). We then conducted a second set of regressions using these residualized scores to examine the independent trajectories of the two attachment dimensions. Results from these analyses were very similar to those 


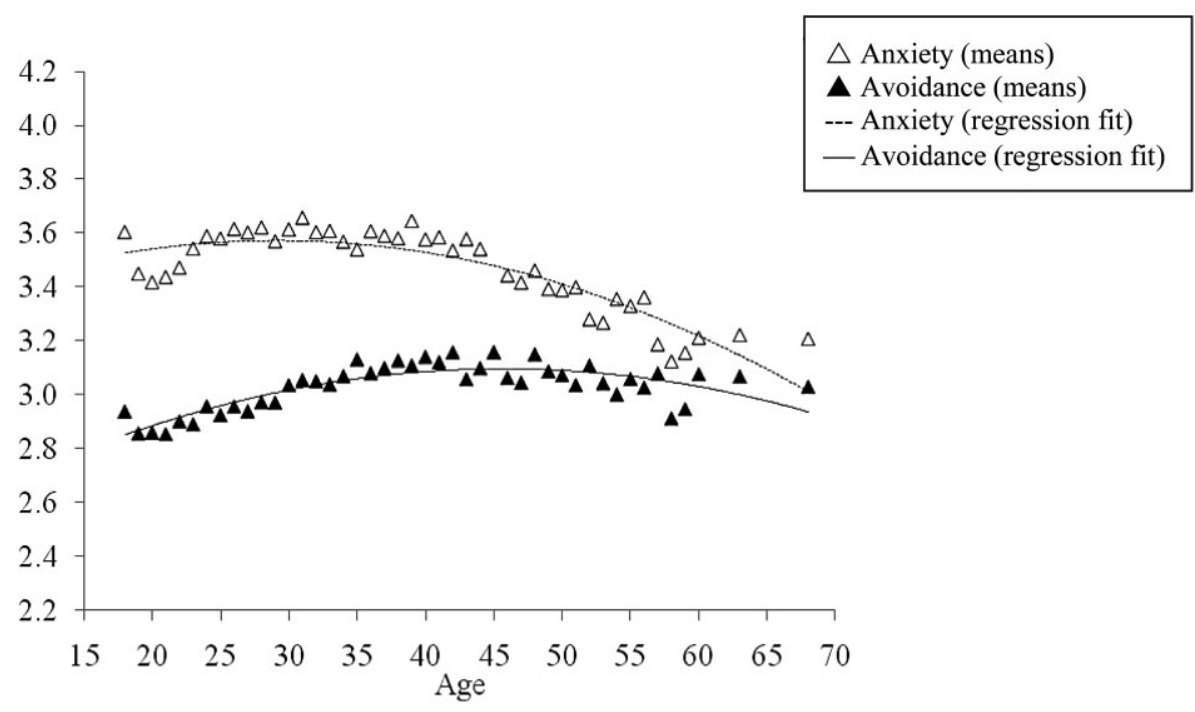

Figure I Age differences in attachment avoidance and anxiety. Points represent means for individual years, with ages 60 and above collapsed into 5 -year increments (i.e., 6I-65, 66-70) because of smaller sample sizes.

Table 2 Regressions Predicting Attachment Dimensions From Age, Gender, and Relationship Status

\begin{tabular}{|c|c|c|c|c|c|c|}
\hline Regression Term & B & SE & $\beta$ & $t$ & $p$ & $F_{\text {change }}$ \\
\hline Constant & 3.98 & .02 & & & & \\
\hline Gender & -.05 & .01 & -.03 & -5.88 & $<.001$ & 34.56 \\
\hline Relationship Status & -.54 & .02 & -.18 & -31.65 & $<.001$ & 1001.88 \\
\hline Age $\times$ Gender & -.001 & .001 & -.01 & -1.88 & .06 & 3.53 \\
\hline $\mathrm{Age}^{2}$ & -.0006 & .000 & -.09 & -15.72 & $<.001$ & 247.09 \\
\hline $\mathrm{Age}^{2} \times$ Gender & .0002 & .000 & .03 & 4.80 & $<.001$ & 23.00 \\
\hline $\mathrm{Age}^{2} \times$ Relationship Status & -.0001 & .000 & -.01 & -2.00 & $<.05$ & 3.99 \\
\hline Age $\times$ Gender $\times$ Rel. Status & .002 & .001 & .02 & 2.37 & $<.05$ & 5.63 \\
\hline Age $^{2} \times$ Gender $\times$ Rel. Status & -.0001 & .000 & -.01 & -1.28 & .20 & 1.63 \\
\hline \multicolumn{7}{|l|}{ Avoidance } \\
\hline Age $\times$ Gender & .001 & .001 & .01 & 2.18 & $<.05$ & 4.73 \\
\hline Age $\times$ Relationship Status & .01 & .001 & .08 & 14.87 & $<.001$ & 221.16 \\
\hline Gender $\times$ Rel. Status & .05 & .01 & .04 & 6.28 & $<.001$ & 39.49 \\
\hline $\mathrm{Age}^{2}$ & -.0006 & .000 & -.08 & -15.22 & $<.001$ & 231.60 \\
\hline $\mathrm{Age}^{2} \times$ Gender & .00001 & .000 & .002 & .31 & .76 & .10 \\
\hline Age $^{2} \times$ Relationship Status & -.0002 & .000 & -.03 & -5.16 & $<.001$ & 26.61 \\
\hline Age $\times$ Gender $\times$ Rel. Status & -.0005 & .001 & -.004 & -.82 & .41 & .68 \\
\hline Age $^{2} \times$ Gender $\times$ Rel. Status & -.00001 & .000 & -.002 & -.30 & .76 & .09 \\
\hline
\end{tabular}

Note. $N=86,225$. Equation for anxiety, $F(I I, 86,214)=303.79, R=.19, p<.00 I$; Equation for avoidance, $F(I I, 86,214)=640.34, R=.28, p<.00 I$; gender: $-I=$ female, $\mathrm{I}=$ male; relationship status: $-\mathrm{I}=$ single, $\mathrm{I}=$ in a relationship.

presented in Table 2, with the exception that for anxiety, the Age $\times$ Gender and Age $\times$ Relationship Status interactions became significant. Decomposing the Age $\times$ Relationship Status interaction (not pictured) revealed that differences in attachment anxiety between younger and older adults were larger among partnered participants compared to single participants. There were no changes in the results for attachment avoidance. 
a.

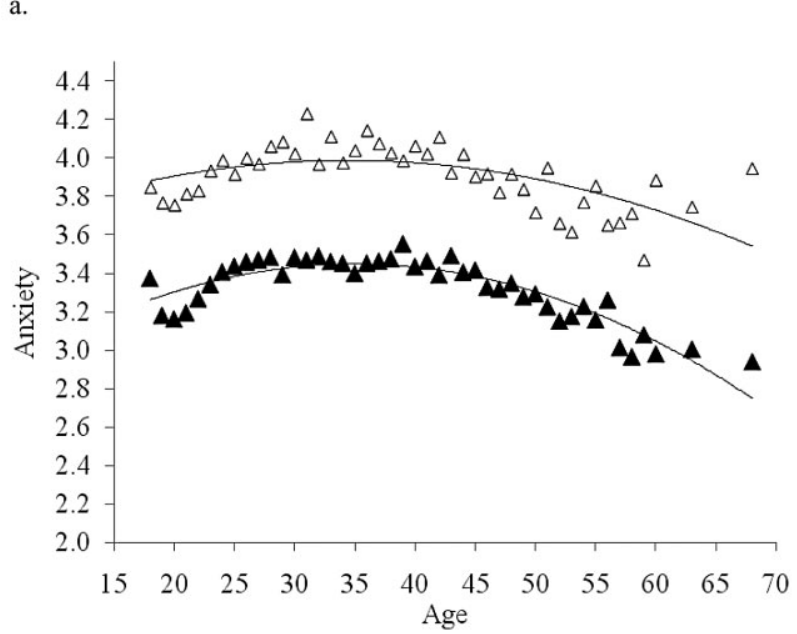

$$
\begin{aligned}
& \triangle \text { Single (means) } \\
& \Delta \text { Partnered (means) } \\
& \text {--- Single (regression fit) } \\
& \text { - Partnered (regression fit) }
\end{aligned}
$$

b.

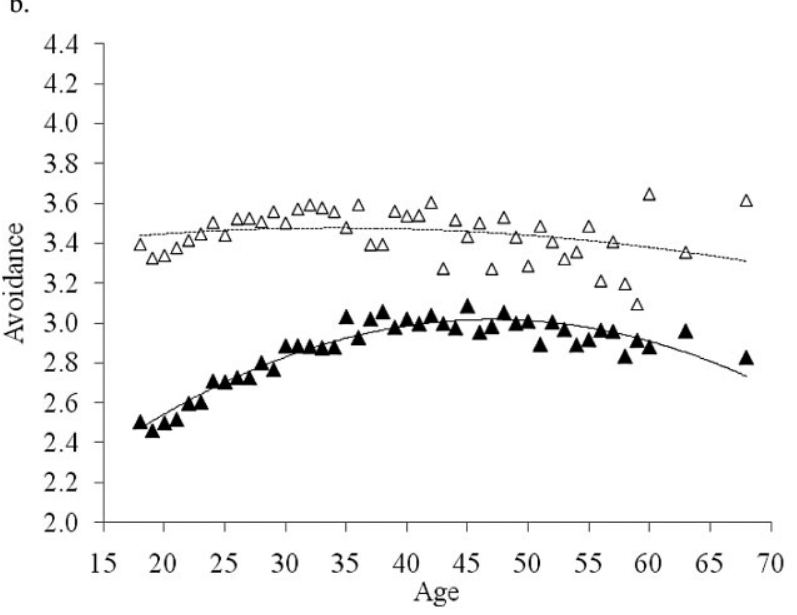

$\triangle$ Single (means)

$\Delta$ Partnered (means)

--- Single (regression fit)

- Partnered (regression fit)

Figure 2 Age differences in attachment anxiety (a) and avoidance (b) for single versus partnered participants. Points represent means for individual years, with ages 60 and above collapsed into 5 -year increments (i.e., 6I-65, 66-70) because of smaller sample sizes.

\section{DISCUSSION}

The current study provides a more comprehensive picture of attachment orientations across the adult life span than has been available in previous research. We examined associations among age, relationship status, gender, and attachment orientation in a sample of 86,555 participants ranging in age from 18 to 70 . Our findings revealed that attachment anxiety was highest among younger adults and lowest among middle-aged and older adults. Attachment avoidance showed less dramatic age differences, but it was higher in middle-aged adults and lower in younger and older adults. Moreover, single participants were higher in both attachment anxiety and avoidance in each age group compared to those who were partnered, and the difference for avoidance was greatest among young adults. Finally, women generally reported higher levels of attachment anxiety and avoidance than men, and the difference for anxiety was greatest in early adulthood. Although prior research alludes to some of these findings, past studies were limited by relatively small sample sizes, narrow age ranges, and a reliance on categorical measures of attachment. The current study addresses these methodological shortcomings and details age differences in adult attachment that fit well with the literature on life span personality development and the factors that shape developmental differences.

The age-related differences that we observed are consistent with theories about changing social roles across the life span and the influence of these roles on personality development (Roberts et al., 2005). Early adulthood is characterized by the adoption of social roles involving close relationships, and normative personality changes during this period facilitate the adoption of such roles (Srivastava et al., 2003). Our findings indicate that attachment anxiety is lower in middle-aged adults and among partnered individuals. This particular age difference in anxiety has at least two possible explanations: Age differences in anxiety are likely to facilitate emotional bonding 

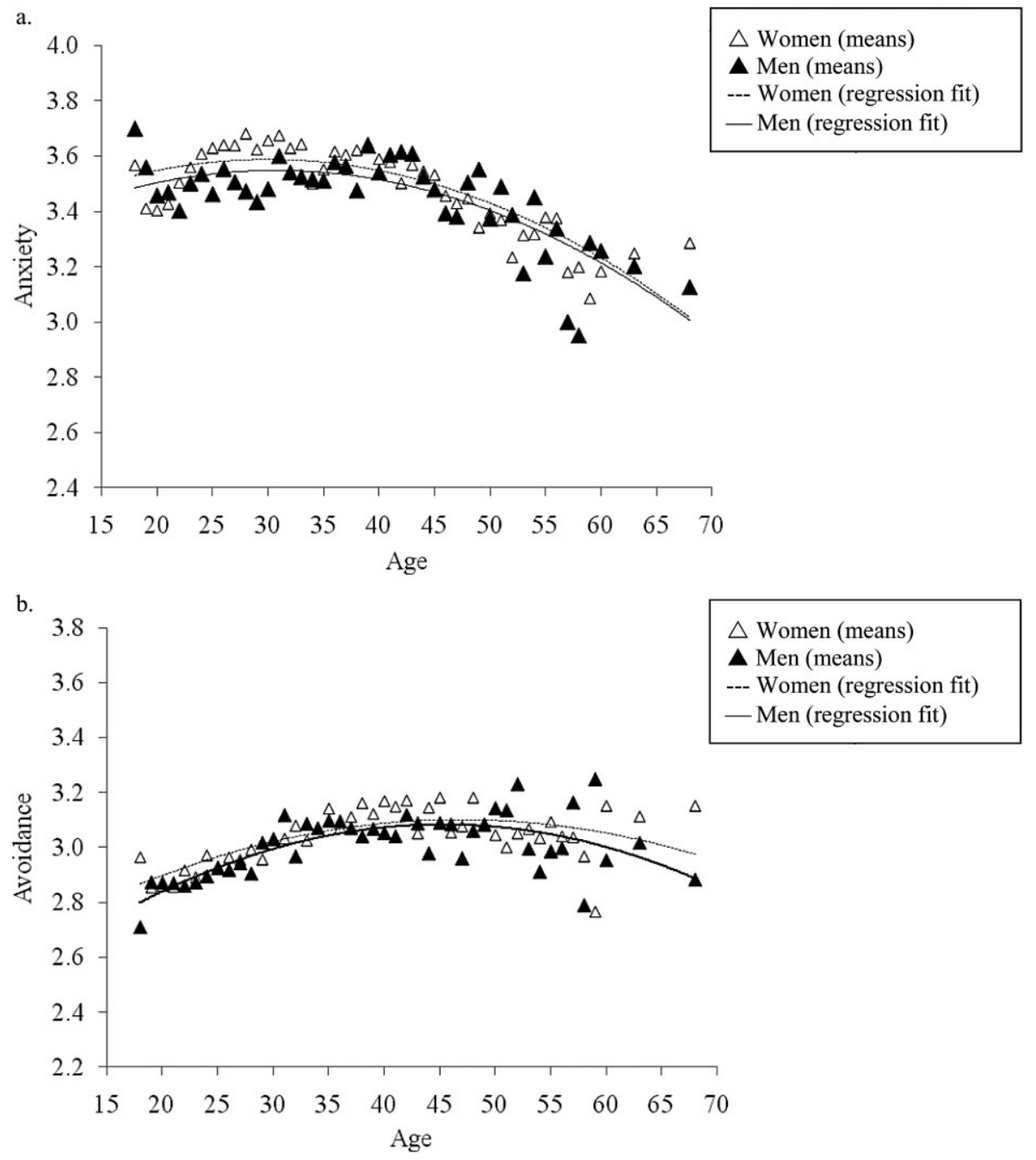

Figure 3 Age differences in attachment anxiety (a) and avoidance (b) for men versus women. Points represent means for individual years, with ages 60 and above collapsed into 5 -year increments (i.e., 61-65, 66-70) because of smaller sample sizes.

to partners and children, as becoming a romantic partner or a parent is accompanied by a new set of responsibilities and expectations. Differences in personality could reflect an effort to change one's personality and behavior to meet the challenges that these new roles present (Roberts et al., 2005). However, the influence of emotional bonds is likely to be felt long after they are initially forged. As such, life span differences in anxiety may also reflect the security-enhancing effects of such bonds once established (Davila et al., 1999). The expectations involved in being a romantic partner exert social control over behavior by rewarding appropriate behavior and admonishing inappropriate behavior, based on a set of contingencies (Roberts et al., 2005). We suggest that, by investing in these social roles, individuals "buy into" these contingencies and are likely to become more secure as their relationships dictate appropriate interpersonal behavior.

It is also important to note, however, that anxiety showed a noticeable dip among participants between the ages of 18 to 20 (see Figure 1), with higher levels of anxiety observed among adults in their mid-20s. Although speculative, it is possible that these differences reflect the individuation processes of late adolescence and the adjustments involved in shifting attachment needs from parents to peers and romantic partners (Fraley \& Davis, 1997). It is worth noting that this pattern of findings is most pronounced among partnered individuals, who may be more likely to depend on partners to meet their attachment needs. The relationship dynamics of younger adults today may also be very different than the experiences of older adults in previous decades (Konrath, Chopik, Hsing, \& O'Brien, 2012). Younger adults may prefer more casual relationships rather than full-blown committed relationships, and as a result, they may report lower anxiety compared to their older counterparts. However, being slightly lower in anxiety during this period may also help individuals initially ease into the role of romantic partner, suggesting that attachment may also influence the rate at which individuals form relationships. 
We also found that avoidance was higher among middleaged adults compared to younger and older adults, and that this pattern was most evident for partnered individuals. Although there is some prior evidence that avoidance is higher among middle-aged adults (e.g., Mickelson et al., 1997), the reasons for such differences are not entirely clear. Higher levels of avoidance among middle-aged adults may reflect the culmination of an individuation process and increasing levels of independence that began during young adulthood (Stewart \& Ostrove, 1998; Zucker, Ostrove, \& Stewart, 2002). Although we can only speculate on the utility of these age differences in avoidance among partnered participants, we hypothesize that they serve a similar function as narcissism in identity development among adolescents and emerging adults (Hill \& Roberts, 2012). In the way that certain facets of narcissism facilitate a smooth transition into adulthood, high levels of avoidance could calm some of the anxiety surrounding relationship formation and maintenance (e.g., becoming a parent, childrearing for many years, sacrificing one's personal goals for a partner, encounters with relationship strife). The higher levels of avoidance among middle-aged partnered participants could partially reflect this process, but only follow-up investigations can appropriately assess the extent to which this pattern is adaptive. However, that age differences in avoidance were relatively small in the overall sample suggests that these differences may be helpful during emerging adulthood but may not be large enough to prevent the formation of a committed romantic relationship altogether (Schindler et al., 2010). Future studies of intra-individual change could provide important information about whether some individuals show more change than others and the reasons for such differences. ${ }^{5}$

Future research should examine the origin and utility of these age differences in attachment. For example, Davila and colleagues (1999) discovered that newlyweds became more secure over the first 2 years of marriage. However, newlyweds who reported lower relationship satisfaction actually became less secure over this 2-year period. In another longitudinal study, one partner's satisfaction and communication behavior predicted changes in attachment style up to 9 months later, suggesting that some of the age differences observed in the current study could be attributed to relationship quality and interpersonal behavior. Kirkpatrick and Hazan (1994) note that relationship breakups, which are likely to occur for many participants, often lead to greater insecurity. Following additional predictions made by the social investment hypothesis, the process of becoming a parent can also have implications for personality development and close relationships. For example, the new expectation to act affectionately and responsibly may result in changes of overall attachment orientations, as some researchers suggest is possible for other traits (Roberts et al., 2005). Indeed, in the transition to parenting, factors involved with family responsibilities and caregiving styles moderate the association between depressive symptoms and attachment insecurity, suggesting that role expectations and behavior have large implications for an adaptive response to adopting and investing in new social roles (Rholes et al., 2011). Lower spousal support and having a partner high in avoidance during the transition to parenthood also predicted increases in attachment anxiety and avoidance, respectively. Similar studies that examine the role of contextual influences and dyadic effects on attachment security at different points in the life span can shed light on the mediators of age differences in attachment orientation.

Of note, however, age differences in anxiety showed a more consistent pattern than those for avoidance, and the patterns for anxiety fit well with the predictions derived from the social investment hypothesis (Roberts et al., 2005). It may be that avoidance is more resistant to changes in social roles compared to anxiety, or potentially less sensitive to environmental influences, so that the effects of being in a relationship are apparent only after longer relationship durations or more relationship experience in general (e.g., experiencing multiple committed relationships across the life span). Evidence that avoidance shows greater longitudinal stability than anxiety (e.g., Klohnen \& John, 1998) is consistent with this idea, but the reasons underlying age differences in attachment and differential change and stability warrant further exploration.

In addition, although prior work suggests that being in a relationship is associated with attachment security (Edelstein \& Gillath, 2008), our study is the first to examine associations between relationship status and attachment orientations across the life span. Our findings indicate that individuals who report being in a close relationship are more secure at each stage of the adult life span, with some of the largest associations with avoidance observed in young adults.

Our findings also contribute important new information about gender differences in attachment and the extent to which such differences exist across the life span. Perhaps one of the most notable observations is how similar men and women are to one another, particularly when examining the pattern of age differences within gender. First, we found that women scored slightly higher on attachment anxiety, particularly in early adulthood. This gender difference is consistent with recent meta-analytic findings (Del Giudice, 2011) and with researchers' claims that because women are more relationship oriented than men, they should report greater attachment anxiety (Magai et al., 2000). Second, we found that women reported slightly higher levels of avoidance than men in early and older adulthood. These findings are inconsistent with meta-analytic evidence that men generally report higher levels of avoidance (Del Giudice, 2011) and with claims that men's lower emotional expression should translate into higher avoidance scores (Pietromonaco \& Carnelley, 1994). However, it is worth noting that Del Giudice found the largest gender differences in community samples, whereas college-aged and Internet samples (such as our own) showed very small or even nonexistent differences. Del Giudice argues that these differences reflect limitations of online studies, such as self-selection based on gender-typed interests or variable male-to-female ratios. However, because Internet samples may be just as diverse as 
community samples and are especially likely to include both younger and older participants (Gosling et al., 2004), it is not yet clear whether divergent findings for avoidance reflect differences in sample composition, survey format, or some combination of the two.

The current findings have many important implications for future research on age-related differences in attachment. For instance, some researchers suggest that attachment measures may be less reliable in older populations, for instance because their internal consistencies are lower in some samples of older adults (Magai, 2008). Anxiety and avoidance subscales in the current study were highly reliable across age groups (see Table 1), highlighting the utility of attachment measures across the adult life span. Our finding that anxiety is lower among middle and older adults may reflect an effort by older adults to increase emotional balance and decrease negative affect (Zhang \& Labouvie-Vief, 2004). By studying how age differences in personality are associated with emotional balance, researchers can generate hypotheses about how middle-aged and older adults encounter and ultimately cope with adversity. Although much of our discussion has focused on relationship and role initiation, individual differences in attachment also have implications for research on bereavement and loss (Shaver \& Fraley, 2008), the likelihood of which increases with age. Future research may be able to shed light on associations among life span attachment processes, coping strategies, and resilience in the face of loss.

Of course, as with any cross-sectional study, our data cannot speak to the causal relations among the variables we have measured. For instance, do close relationships promote attachment security, as we have proposed, or are more secure participants more likely to establish close relationships (Schindler et al., 2010)? Because we did not include any questions about relationship history in this study, we cannot know how long these individuals had been single or how much relationship experience single participants may have had. For example, a participant who has been single for 40 years, a recent divorcé, and a recent widow(er) all have very different relationship histories and experiences, but our current conceptualization of relationship status is not nuanced enough to make this distinction. However, there is longitudinal evidence suggesting that relationships have security-enhancing effects (Davila et al., 1999) and that changes in relationship status can have large effects on attachment orientation (Davila \& Bradbury, 2001; Kirkpatrick \& Hazan, 1994). The few studies that have examined longitudinal changes in married couples converge well with the patterns of age differences observed in the current study, such that attachment anxiety decreases over time, but an individual's comfort with closeness (similar to low attachment avoidance) showed little to no significant changes (Davila et al., 1999). Also, anxious and secure individuals do not differ in their ability to maintain a relationship over a 4-year period (Kirkpatrick \& Hazan, 1994), indicating that relationship status may be a stable variable for these analyses. Kirkpatrick and Hazan also found that secure individuals reported fewer breakups than insecure individuals during this time period, suggesting a low likelihood that a highly secure person was single by choice at the time of data collection.

Including measures of relationship history and experience could have allowed for finer distinctions of an individual's relationship status, such as those who casually date or are in committed relationships. One longitudinal study examined the role of attachment in predicting whether individuals start casually dating or begin committed relationships (Schindler et al., 2010), a distinction that could inform the results of our study. In Schindler and colleagues' study, in comparing individuals who began casually dating and individuals who started a committed relationship, participants low in avoidance were most likely to start a committed relationship over the course of the study. This association held even after controlling for an individual's explicit goals to start a committed relationship, prior dating history, self-perceived attractiveness, and attachment anxiety. The study by Schindler and colleagues (2010) suggests that although age differences in attachment may be associated with the types of roles we adopt across the life span, attachment is still a predictor of the degree to which we immerse ourselves in a social role. Future research can examine how attachment orientation and relationship goals among middle-aged and older adults are related to relationship initiation and maintenance at different points in the life span.

Another limitation of our study is that we did not measure characteristics of the relationship (e.g., satisfaction, commitment), which have been shown to be important determinants of attachment security in the early years of relationships (Davila \& Bradbury, 2001; Davila et al., 1999). Future research should examine how these features interact to influence attachment orientation at different points in the life span. It is also impossible to know whether the age-related differences we observed are the result of developmental changes in attachment orientation (Klohnen \& John, 1998) or cohort effects (Magai et al., 2001). For example, specific characteristics of one group of individuals (i.e., those born in the 1990s) could partially explain why younger adults were lower in attachment avoidance or higher in anxiety compared to middle-aged adults (as we observed in our study). The possibility of cohort effects would undermine a developmental interpretation by attributing age differences to societal factors specific to a particular group (i.e., sociocultural norms). Perhaps the growing demands of society have led to an "age of anxiety" for more recent cohorts (Twenge, 2000). Technology may also bring people closer together than ever before and therefore reduce avoidance.

One way to separate the effects of birth cohort from age is to analyze samples of people of the same age from different cohorts. By comparing individuals who are similar on nearly every demographic characteristic, one can examine how they differ according to when the data were collected (a proxy for cohort). Researchers would then be able to test the hypothesis that anxiety is higher and avoidance is lower in more recent cohorts (as our data have shown). A recent cross-temporal meta-analysis of American college students from 1988 to 2010 
tested this hypothesis. The meta-analysis revealed that American college students have been increasing in one form of attachment avoidance (dismissing attachment) from 1997 to the present, but there has been no such change among any other attachment orientations (Konrath et al., 2012). This study would suggest that in a cross-sectional study, we might expect mean levels of avoidance to be greatest among those currently in young adulthood, with older participants showing lower levels of avoidance. Instead, the current findings indicate that young adults reported lower levels of attachment avoidance compared to middle-aged adults. We also found dramatic age differences for attachment anxiety, in contrast to the crosstemporal meta-analysis. Although our findings are generally consistent with extant longitudinal research (Klohnen \& John, 1998) showing that anxiety decreases and avoidance remains relatively stable across the life span, only further longitudinal studies can appropriately differentiate cohort effects from normative developmental changes (Roberts, Edmonds, \& Grijalva, 2010).

Despite these limitations, the present study represents a crucial step toward understanding attachment dynamics across the life span. We have documented important age-related differences in attachment orientations and the extent to which these differences are associated with gender and relationship status. These novel findings advance life span perspectives on attachment research and highlight the importance of social role theories on personality development.

\section{Notes}

1. A small number of participants did not report their gender $(n=159)$ or relationship status $(n=172)$ and are therefore excluded from analyses including these variables.

2. The cubic terms of age for both anxiety $\left(F_{\text {change }}=7.32\right)$ and avoidance $\left(F_{\text {change }}=2.37\right)$ fell short of the criteria for overall model fit.

3. The addition of the cubic terms for the moderating effects of gender and relationship status for both anxiety $\left(F_{\text {change }}=15.30\right)$ and avoidance $\left(F_{\text {change }}=6.73\right)$ fell short of the criteria for overall model fit. We therefore discuss the regression models involving only quadratic and linear terms.

4. Figure $3 b$ depicts age differences in avoidance for men versus women. However, none of these effects surpassed our criteria for overall model fit.

5. We should make it clear that age should not be taken as a simple proxy for relationship length. It could very well be the case that, holding age constant, avoidance is lower among individuals who have been in relationships for longer periods of time than those who are involved in relationships of a shorter duration.

\section{References}

Arnett, J. J. (2000). Emerging adulthood: A theory of development from the late teens through the twenties. American Psychologist, 55, 469-480.
Birnbaum, G. (2007). Attachment orientations, sexual functioning, and relationship satisfaction in a community sample of women. Journal of Social and Personal Relationships, 24, 21-35.

Bowlby, J. (1969/1982). Attachement and loss: Attachment (Vol. 1). New York: Basic Books.

Bowlby, J. (1973). Attachment and loss: Separation: Anxiety and anger (Vol. 2). New York: Basic Books.

Brennan, K. A., Clark, C. L., \& Shaver, P. R. (1998). Self-report measurement of adult attachment: An integrative overview. In J. A. Simpson \& W. S. Rholes (Eds.), Attachment theory and close relationships. (pp. 46-76). New York: Guilford Press.

Carstensen, L. L., Isaacowitz, D. M., \& Charles, S. T. (1999). Taking time seriously: A theory of socioemotional selectivity. American Psychologist, 54, 165-181.

Cassidy, J., \& Shaver, P. R. (2008). Handbook of attachment: Theory, research, and clinical applications (2nd ed.). New York: Guilford Press.

Consedine, N. S., Magai, C., \& Krivoshekova, Y. S. (2005). Sex and age cohort differences in patterns of socioemotional functioning in older adults and their links to physical resilience. Ageing International, 30, 209-243.

Cross, S., \& Madson, L. (1997). Models of the self: Self-construals and gender. Psychological Bulletin, 122, 5-37.

Davila, J., \& Bradbury, T. N. (2001). Attachment insecurity and the distinction between unhappy spouses who do and do not divorce. Journal of Family Psychology, 15, 371-393.

Davila, J., Karney, B. R., \& Bradbury, T. N. (1999). Attachment change processes in the early years of marriage. Journal of Personality and Social Psychology, 76, 783-802.

Del Giudice, M. (2011). Sex differences in romantic attachment: A meta-analysis. Personality and Social Psychology Bulletin, 37, 193-214.

Diehl, M., Elnick, A. B., Bourbeau, L. S., \& Labouvie-Vief, G. (1998). Adult attachment styles: Their relations to family context and personality. Journal of Personality and Social Psychology, 74, 1656-1669.

Edelstein, R. S., \& Gillath, O. (2008). Avoiding interference: Adult attachment and emotional processing biases. Personality and Social Psychology Bulletin, 34, 171-181.

Edelstein, R. S., \& Shaver, P. R. (2004). Avoidant attachment: Exploration of an oxymoron. In D. J. Mashek \& A. P. Aron (Eds.), Handbook of closeness and intimacy (pp. 397-412). Mahwah, NJ: Erlbaum.

Erikson, E. H. (1968). Identity: Youth and crisis. New York: Norton.

Fraley, R. C., \& Davis, K. E. (1997). Attachment formation and transfer in young adults' close friendships and romantic relationships. Personal Relationships, 4, 131-144.

Fraley, R. C., \& Shaver, P. R. (1997). Adult attachment and the suppression of unwanted thoughts. Journal of Personality and Social Psychology, 73, 1080-1091.

Fraley, R. C., \& Shaver, P. R. (2000). Adult romantic attachment: Theoretical developments, emerging controversies, and unanswered questions. Review of General Psychology, 4, 132-154.

Fraley, R. C., \& Waller, N. G. (1998). Adult attachment patterns: A test of the typological model. In J. A. Simpson \& W. S. Rholes 
(Eds.), Attachment theory and close relationships. (pp. 77-114). New York: Guilford Press.

Fraley, R. C., Waller, N. G., \& Brennan, K. A. (2000). An item response theory analysis of self-report measures of adult attachment. Journal of Personality and Social Psychology, 78, 350-365.

Gosling, S. D., Vazire, S., Srivastava, S., \& John, O. P. (2004). Should we trust Web-based studies? A comparative analysis of six preconceptions about Internet questionnaires. American Psychologist, 59, 93-104.

Gross, J. J., Carstensen, L. L., Pasupathi, M., Tsai, J., Skorpen, C. G., \& Hsu, A. Y. C. (1997). Emotion and aging: Experience, expression, and control. Psychology and Aging, 12, 590-599.

Hazan, C., \& Shaver, P. (1987). Romantic love conceptualized as an attachment process. Journal of Personality and Social Psychology, 52, 511-524.

Hill, P. L., \& Roberts, B. W. (2012). Narcissism, well-being, and observer-rated personality across the lifespan. Social Psychological and Personality Science, 3, 216-223.

Kirkpatrick, L. A., \& Hazan, C. (1994). Attachment styles and close relationships: A four-year prospective study. Personal Relationships, 1, 123-142.

Klohnen, E. C., \& John, O. P. (1998). Working models of attachment: A theory-based prototype approach. In J. A. Simpson \& W. S. Rholes (Eds.), Attachment theory and close relationships (pp. 115-140). New York: Guilford Press.

Konrath, S. H., Chopik, W. J., Hsing, C., \& O’Brien, E. H. (2012). Dismissing attachment styles are increasing in American college students over time: A meta-analysis. Manuscript submitted for publication.

Magai, C. (2008). Attachment in middle and later life. In J. Cassidy \& P. R. Shaver (Eds.), Handbook of attachment: Theory, research, and clinical applications (2nd ed., pp. 532-551). New York: Guilford Press.

Magai, C., Cohen, C., Milburn, N., Thorpe, B., McPherson, R., \& Peralta, D. (2001). Attachment styles in older European American and African American adults. Journals of Gerontology: Series B: Psychological Sciences and Social Sciences, 56B(1), S28S35.

Magai, C., Hunziker, J., Mesias, W., \& Culver, L. C. (2000). Adult attachment styles and emotional biases. International Journal of Behavioral Development, 24, 301-309.

Mickelson, K. D., Kessler, R. C., \& Shaver, P. R. (1997). Adult attachment in a nationally representative sample. Journal of Personality and Social Psychology, 73, 1092-1106.

Mikulincer, M., \& Florian, V. (1998). The relationship between adult attachment styles and emotional and cognitive reactions to stressful events. In J. A. Simpson \& W. S. Rholes (Eds.), Attachment theory and close relationships (pp. 143-165). New York: Guilford Press.

Mikulincer, M., Gillath, O., \& Shaver, P. R. (2002). Activation of the attachment system in adulthood: Threat-related primes increase the accessibility of mental representations of attachment figures. Journal of Personality and Social Psychology, 83, 881895.
Noftle, E. E., \& Shaver, P. R. (2006). Attachment dimensions and the Big Five personality traits: Associations and comparative ability to predict relationship quality. Journal of Research in Personality, 40, 179-208.

Otway, L. J., \& Vignoles, V. L. (2006). Narcissism and childhood recollections: A quantitative test of psychoanalytic predictions. Personality and Social Psychology Bulletin, 32, 104-116.

Pietromonaco, P. R., \& Carnelley, K. B. (1994). Gender and working models of attachment: Consequences for perceptions of self and romantic relationships. Personal Relationships, 1, 63-82.

Rholes, W. S., Simpson, J. A., Kohn, J. L., Wilson, C. L., Martin, A. M., III, Tran, S., et al. (2011). Attachment orientations and depression: A longitudinal study of new parents. Journal of Personality and Social Psychology, 100, 567-586.

Roberts, B. W., Edmonds, G., \& Grijalva, E. (2010). It is developmental me, not generation me: Developmental changes are more important than generational changes in narcissism - Commentary on Trzesniewski \& Donnellan (2010). Perspectives on Psychological Science, 5, 97-102.

Roberts, B. W., Wood, D., \& Smith, J. L. (2005). Evaluating five factor theory and social investment perspectives on personality trait development. Journal of Research in Personality, 39, 166-184.

Schindler, I., Fagundes, C. P., \& Murdock, K. W. (2010). Predictors of romantic relationship formation: Attachment style, prior relationships, and dating goals. Personal Relationships, 17, 97-105.

Segal, D. L., Needham, T. N., \& Coolidge, F. L. (2009). Age differences in attachment orientations amoung younger and older adults: Evidence from two self-report measures of attachment. International Journal of Aging and Human Development, 69, 119-132.

Shaver, P. R., \& Fraley, R. C. (2008). Attachment, loss, and grief: Bowlby's views and current controversies. In J. Cassidy \& P. R. Shaver (Eds.), Handbook of attachment: Theory, research, and clinical applications (2nd ed., pp. 48-77). New York: Guilford Press.

Smolewska, K., \& Dion, K. L. (2005). Narcissism and adult attachment: A multivariate approach. Self and Identity, 4, 59-68.

Soto, C. J., John, O. P., Gosling, S. D., \& Potter, J. (2011). Age differences in personality traits from 10 to 65 : Big Five domains and facets in a large cross-sectional sample. Journal of Personality and Social Psychology, 100, 330-348.

Srivastava, S., John, O. P., Gosling, S. D., \& Potter, J. (2003). Development of personality in early and middle adulthood: Set like plaster or persistent change? Journal of Personality and Social Psychology, 84, 1041-1053.

Stewart, A. J., \& Ostrove, J. M. (1998). Women's personality in middle age: Gender, history, and midcourse corrections. American Psychologist, 53, 1185-1194.

Terracciano, A., McCrae, R. R., Brant, L. J., \& Costa, P. T. (2005). Hierarchical linear modeling analyses of NEO-PI-R scales in the Baltimore Longitudinal Study of Aging. Psychology and Aging, 20, 493-506.

Twenge, J. M. (2000). The age of anxiety? The birth cohort change in anxiety and neuroticism, 1952-1993. Journal of Personality and Social Psychology, 79, 1007-1021. 
Whitbourne, S. K., \& Tesch, S. A. (1985). A comparison of identity and intimacy statuses in college students and alumni. Developmental Psychology, 21, 1039-1044.

Zeifman, D., \& Hazan, C. (1997). Attachment: The bond in pairbonds. In J. A. Simpson \& D. T. Kenrick (Eds.), Evolutionary social psychology (pp. 237-263). Hillsdale, NJ: Erlbaum.
Zhang, F., \& Labouvie-Vief, G. (2004). Stability and fluctuation in adult attachment style over a 6-year period. Attachment \& Human Development, 6, 419-437.

Zucker, A. N., Ostrove, J. M., \& Stewart, A. J. (2002). Collegeeducated women's personality development in adulthood: Perceptions and age differences. Psychology and Aging, 17, 236-244. 